\title{
Correction to: An optical method for rapid examination of check development in decorative plywood panels
}

\author{
Michael David Burnard ${ }^{1,2,3} \cdot$ Lech Muszyński $^{4} \cdot$ Scott Leavengood $^{4} \cdot$ Lisa Ganio $^{5}$
}

Published online: 21 November 2018

c) Springer-Verlag GmbH Germany, part of Springer Nature 2018

\section{Correction to: \\ European Journal of Wood and Wood Products (2018) 76:1367-1377 \\ https://doi.org/10.1007/s00107-018-1327-7}

In the original publication, a recent source of funding was not included in the acknowledgements section. The complete acknowledgements section should read as follows.

Acknowledgements This project was funded by the United States Department of Agriculture Special Grant program for Wood Utilization Research with generous contributions from the members of the Western Hardwood Plywood Producers-Columbia Forest Products, Murphy Plywood, Roseburg Forest Products, States Industries and Timber Products Company. Michael Burnard gratefully acknowledges funding received from the European Union's Horizon 2020 research and innovation programme under grant agreement no. 739574 .

Publisher's Note Springer Nature remains neutral with regard to jurisdictional claims in published maps and institutional affiliations.

The original article can be found online at https://doi.org/10.1007/ s00107-018-1327-7.

Michael David Burnard

michael.burnard@iam.upr.si

1 Andrej Marušič Institute, University of Primorska, Muzejski $\operatorname{trg}$ 2, 6000 Koper, Slovenia

2 Abelium, d.o.o., Kajuhovu 90, 1000 Ljubljana, Slovenia

3 InnoRenew CoE, Livade 6, 6310 Izola, Slovenia

4 Department of Wood Science and Engineering, College of Forestry, Oregon State University, 119 Richardson Hall, Corvallis, OR 97331, USA

5 Department of Forest Ecosystems and Society, College of Forestry, Oregon State University, 321 Richardson Hall, Corvallis, OR 97331, USA 